\title{
Steroid-sparing effects and acceptability of a new skin gel containing the anti-inflammatory medicinal substance-nicotinamide
}

This article was published in the following Dove Press journal:

Clinical, Cosmetic and Investigational Dermatology

\author{
Jasmina Djokic-Gallagher \\ Phil Rosher \\ Valerie Hart \\ Jennine Walker
}

Research and Development, Dermal Laboratories Ltd, Hitchin, SG4 7QR, UK
Correspondence: Jasmina DjokicGallagher

Research and Development, Dermal Laboratories Ltd, Hitchin SG4 7QR, UK

Tel +440 I46 2458866

Fax +44 $0 \quad 1462438707$

Email Jasmina.Gallagher@dermal.co.uk
Background/aim: Adex gel (DENI) is a leave-on emollient, containing an ancillary antiinflammatory medicinal substance, nicotinamide, for use in the treatment and management of dry skin conditions prone to inflammation. The aim of the study was to obtain patients' and a Medical Investigator's feedback on the clinical performance and acceptability of the product, and to assess the product's potential for reducing patients' reliance on topical corticosteroids and immunomodulators.

Methods: Forty-eight patients were enrolled with 43 patients completing the study. These patients used the product on its own, or as adjunctive therapy, for two weeks instead of their usual emollient, applying it three times daily or more often if necessary. Using a questionnaire, subjects then indicated whether they were in agreement or not with various statements about the clinical performance and acceptability of the product. In the second part of the study, twenty patients used the product for four weeks, this time using it as often as they liked. The Medical Investigator looked at both the performance and the acceptability of the treatment. Patients completed a questionnaire again to indicate how they used it and whether their use of topical corticosteroids and/or immunomodulator treatments had changed.

Results: Patient's responses were very positive, ranging from $81 \%$ to $100 \%$ agreement with each performance statement in relation to beneficial effects on the skin. The Medical Investigator considered that for nearly all patients, DENI gel was a helpful and convenient addition to their treatment regime. When questioned on steroid-sparing effects, more than half reported that they needed to use less of their other anti-inflammatory treatments, and nearly $95 \%$ reported that they felt their skin condition had benefited from using DENI gel. Conclusion: This new anti-inflammatory emollient appears to be a helpful addition to the treatment armamentarium for eczema and psoriasis that may reduce reliance on topical corticosteroids and immunomodulators.

Keywords: nicotinamide, emollient, steroid sparing effect, evidence

\section{Introduction}

Atopic eczema (AE) is a common, chronic, inflammatory skin disease. ${ }^{1}$ Due to loss of skin barrier function, generalised skin dryness is commonly observed, with some areas exhibiting inflammation that frequently become itchy. ${ }^{2}$

The first line treatment for $\mathrm{AE}$ is emollient therapy. Emollients predominantly work by increasing skin water content. ${ }^{3-5}$ They typically contain both oily occlusive substances, such as mineral oils, which form an occlusive barrier on the surface of the skin to decrease evaporation of water from beneath, and 
humectant substances, such as glycerol and urea, which attract and hold water in the skin. ${ }^{6}$

In many cases additional topical anti-inflammatory therapy is necessary to treat intermittent flares that tend to occurr. ${ }^{7}$ Topical corticosteroids are often used for this purpose but side-effects can occur and so they have to be used cautiously. Immunomodulating drugs, such as tacrolimus and pimecrolimus, are also available but questions remain over their long-term safety.

$\operatorname{Adex}^{\mathrm{TM}}$ gel is a new emollient available in the UK incorporating nicotinamide for its anti-inflammatory action for the treatment and routine management of dry and/or inflamed skin conditions such as mild to moderate AE, various forms of eczema, contact dermatitis and psoriasis. Owing to the well-established safety profile of nicotinamide, this anti-inflammatory emollient is suitable for generalised application and for as long as necessary.

The aim of this study, conducted in two parts, was to assess patients' and a Medical Investigator's feedback on the clinical performance and acceptability of Adex ${ }^{\mathrm{TM}}$ gel (assessed under DENI gel code), Dermal Laboratories Ltd, UK and to assess the product's potential for reducing patients' reliance on topical corticosteroids and immunomodulators.

\section{Clinical study design}

Both parts of the study were conducted with full ethics (Reading Independent Ethics Committee, Reading, UK (RIEC refs. 140317-02 and 130627-01)) and in compliance with the principles of the Declaration of Helsinki and Good Clinical Practice (GCP). Written informed consent was obtained from all subjects.

\section{Part I}

This study was an open, patient evaluation of DENI gel used as approved for routine management of dry and/or inflamed skin conditions such as mild to moderate atopic dermatitis, various forms of eczema, contact dermatitis and psoriasis. Forty-eight patients, aged between 19 and 66 years (mean 39.1 years \pm 14.6 ), 14 males $(29.2 \%$ ) and 34 females $(70.8 \%)$, with these conditions were enrolled and were asked to use the product for two weeks instead of their usual emollient, applying the gel three times daily or more often if necessary. Patients were given a treatment diary in which to record their daily applications and, by completing a questionnaire, patients then indicated whether they "disagreed strongly", "disagreed", "neither disagreed nor agreed", "agreed" or "strongly agreed" with various statements about the clinical performance and acceptability of the product (including its pump pack presentation and the instruction leaflet).

Inclusion criteria were: a) male or female adults at least 18 years of age b) chronic users of emollients for the treatment and routine management of a dry or inflamed skin condition c) willingness to use DENI gel instead of their usual leave-on emollients for 2 weeks. The key exclusion criteria were a) known skin sensitivity or intolerance to any of the ingredients b) any medical condition that could adversely influence their participation in the study c) use of any unlicensed healthcare products within the last 30 days or any other investigative product during the study d) pregnancy and breastfeeding.

There were no restrictions on the use of concomitant medication. Patients could carry on using any other topically applied treatment they customarily used for their skin condition but were asked not to use any other leave-on emollient. Any pre-study use of emollient wash products or bath emollients could continue as normal in addition to applying DENI gel as a leave-on emollient. Patients were also allowed to carry on using their usual facial cosmetics and/or facial moisturisers, as appropriate.

\section{Part 2}

In this part, twenty patients, from the study in Part 1, used the product again (mean 42 years \pm 14.6$), 7$ males $(35 \%)$ and 13 females (65\%), this time for four weeks and applying it as often as necessary in accordance with the Package Leaflet. The Medical Investigator recorded the nature of the patient's skin condition, as confirmed by examination at screening, and also recorded the name(s) of the current emollient(s) used. At the four-week timepoint, the Medical Investigator assessed the patients' condition and completed a questionnaire for each patient rating the products performance. Furthermore, the Medical Investigator also reviewed treatment diaries to assess study compliance. Any adverse events experienced during the 2- or 4-week treatment period were discussed with patients.

At the end of the study, patients completed a questionnaire to indicate, inter alia, how often they used DENI gel and whether their use of topical corticosteroids and/or immunomodulator treatments was "less", "about the same" or "more" than usual. Patients also rated various aspects of the performance and acceptability of the treatment.

As for Part 1, there were no restrictions on the use of any concomitant medication and patients could carry on using any other topically applied treatment they customarily use for their skin condition. They could also continue 
to use their usual facial cosmetics and/or facial moisturisers, as appropriate.

Patients were provided with a CE-marked pack of DENI gel, consisting of a 500 g pump bottle with a Package Leaflet inside a unit carton. The composition of the gel is provided in Table 1. Details of all adverse events or suspected adverse reactions were recorded in the study specific adverse event form.

\section{Results}

\section{Part I}

Forty-eight patients were enrolled in the study with 43 patients completing the study. Three patients were lost to follow up and two withdrew due to suspected adverse reactions. Most patients used DENI gel for the treatment of psoriasis or eczema (Table 2). Patients' responses in relation to clinical performance and key acceptability attributes were very positive, ranging from $81 \%$ to $100 \%$ (Figure 1). In addition, over $85 \%$ of patients gave positive responses for all statements regarding the pump pack presentation and the usefulness of the instruction leaflet (Figures 2 and 3).

Adverse reactions were non-serious and for the majority of patients they were mainly transient itching, stinging or soreness, especially on excoriated skin.

Table I DENI gel composition

\begin{tabular}{|l|}
\hline DENI gel \\
\hline Nicotinamide \\
Liquid Paraffin \\
Isopropyl Myristate \\
Glycerol \\
Carbomer \\
Sorbitan laurate \\
Triethanolamine \\
Phenoxyethanol \\
Purified Water \\
\hline
\end{tabular}

Table 2 Part I - Skin condition frequency table

\begin{tabular}{|l|l|l|}
\hline \multicolumn{2}{|l|}{ Skin Conditions Frequency Table } & $\%$ \\
\hline Skin Condition & No. Patients & 8.3 \\
\hline Atopic dermatitis & 4 & 6.3 \\
Contact dermatitis & 3 & 33.3 \\
Eczema & 16 & 52.1 \\
Psoriasis & 25 & 100 \\
Total & 48 & \\
\hline
\end{tabular}

\section{Part 2}

Twenty patients were enrolled in this part of the study. One was lost to follow up. The remainder completed the study as planned except one patient who could not attend their final visit but nevertheless completed the patient questionnaire. As for part 1, nearly all of the patients treated psoriasis or eczema (Table 3).

At Visit 1, before using DENI gel, patients were asked to list their usual emollient(s) and other products used to treat their skin condition. These are summarised in Tables 4 and 5 .

After using DENI gel for four weeks, the responses to the questionnaire were collected at Visit 2.

When asked whether they used DENI gel on its own or in addition to other treatment(s), eleven patients (57.9\%) responded that they used DENI gel on its own, and 8 patients (42.1\%) responded that they used it in addition to other treatments. Of the 8 latter patients, 3 used it in addition to their usual leave-on emollient(s); 3 patients used it in addition to their usual leave-on emollient(s) plus other usual treatments; 1 patient used it in addition to their other non-emollient usual treatment only (ie did not use their usual leave-on emollient at the same time as DENI gel) and one patient did not specify which treatment(s) they used in addition to DENI gel.

When asked how many times a day, on average, DENI gel was applied, six patients (32\%) responded that they used it on average twice per day, 4 patients (21\%) responded that they used it on average 3 times per day, 2 patients each (11\%) responded that they used it on average $1-2$ or 2-3 times per day and 1 patient each $(5 \%)$ responded that they used it $1-3,3$, or 4 times per day. One patient responded that they used DENI gel twice per day to begin with and then 3 times per day.

Patients generally used about the same amount of DENI gel as their standard emollient (Figure 4) and nearly 95\% reported that they felt their skin condition had benefited from using it (Figure 5). Approximately half of the patients reported that they needed to use less of their other anti-inflammatory treatments. The remainder reported that they used about the same, and nobody stated that they used more of their other anti-inflammatory treatments. Given the choice of applying the product on all affected areas or on only selected areas, and whether to use it every day or only occasionally, $89 \%$ of patients considered DENI gel suitable to apply on all affected areas (Figure 6), and 84\% used it every day (Figure 7).

The Medical Investigator considered that for nearly all patients, DENI gel was a helpful and convenient addition to patients' treatment regime. 


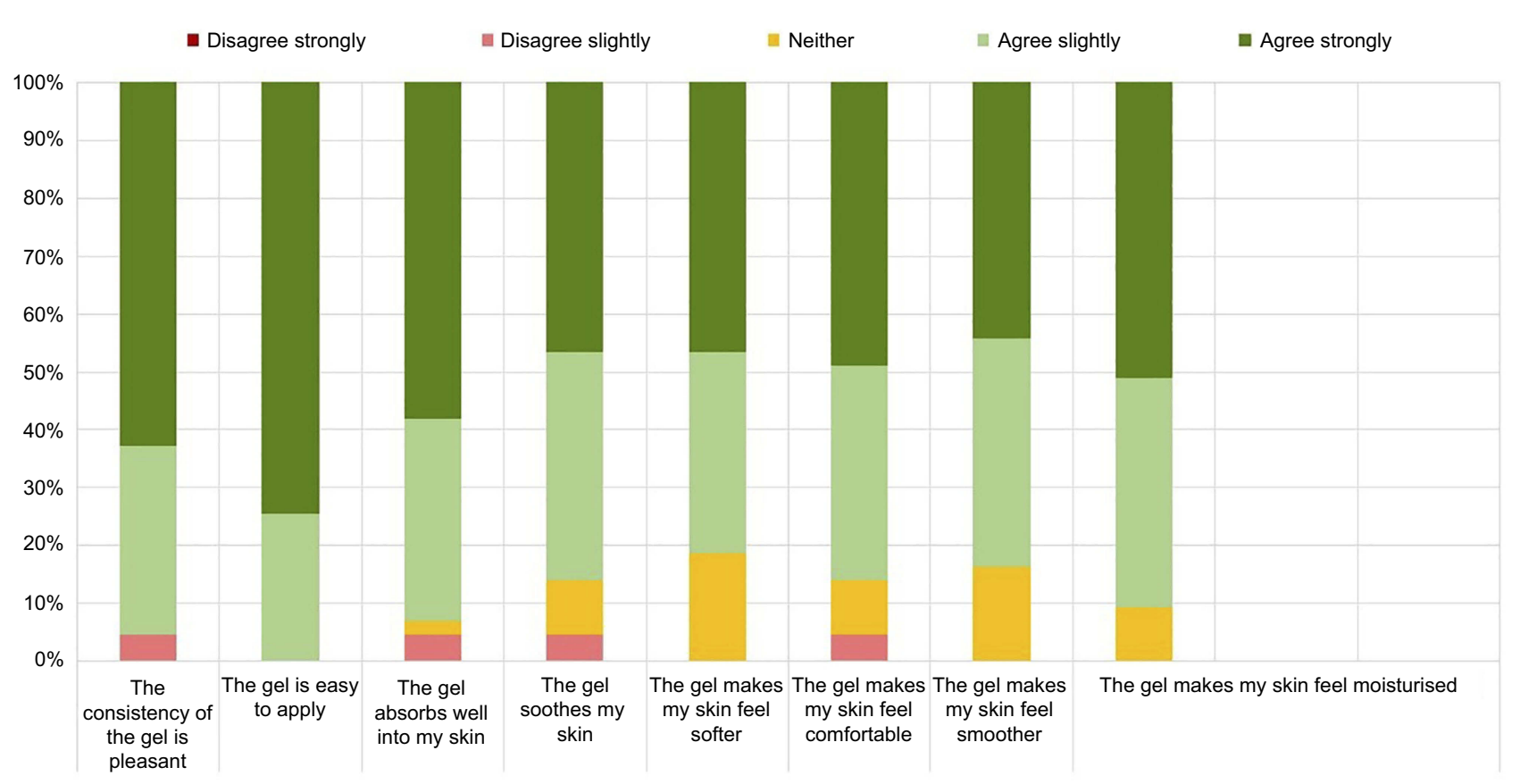

Figure I Clinical performance and acceptability of DENI gel.

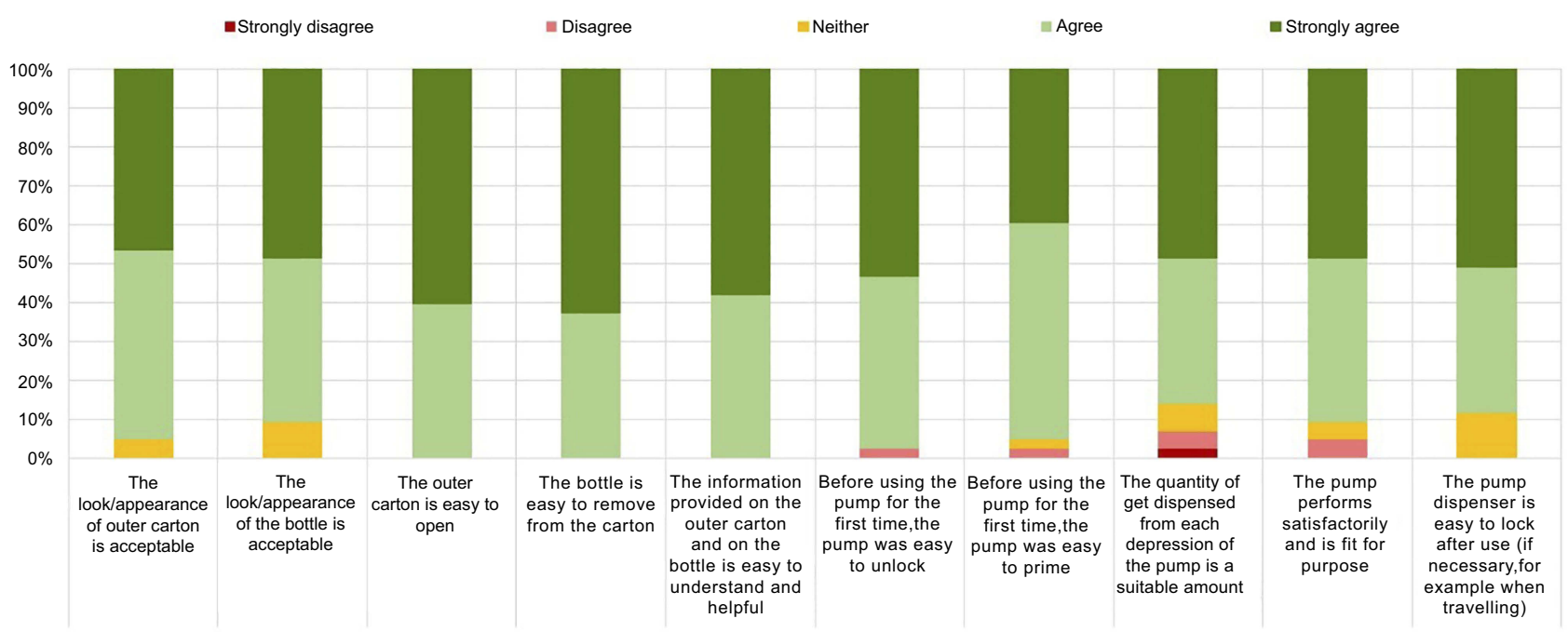

Figure 2 Packaging acceptability.

In this part of the study, reported side effects were similar in nature and frequency to those reported for emollients in general, such as temporary local stinging, especially on excoriated skin.

\section{Discussion}

It is recognised that regardless of the substantial effectiveness of emollients in maintaining the condition of the skin, the majority of $\mathrm{AE}$ and psoriasis patients will experience, more or less frequently, flares in their condition where additional anti-inflammatory medication is necessary. ${ }^{8}$ This is generally in the form of corticosteroids which, because of the well documented adverse effects on the skin resulting from long term use, clinicians need to prescribe carefully, balancing the strength of the corticosteroid with the time taken for it to have the desired effect. ${ }^{9-12}$ The addition of an anti-inflammatory agent, with a better safety profile, to an effective emollient will offer a product which conveniently may be used in the same way as an emollient. ${ }^{13,14}$ The added anti-inflammatory activity will 


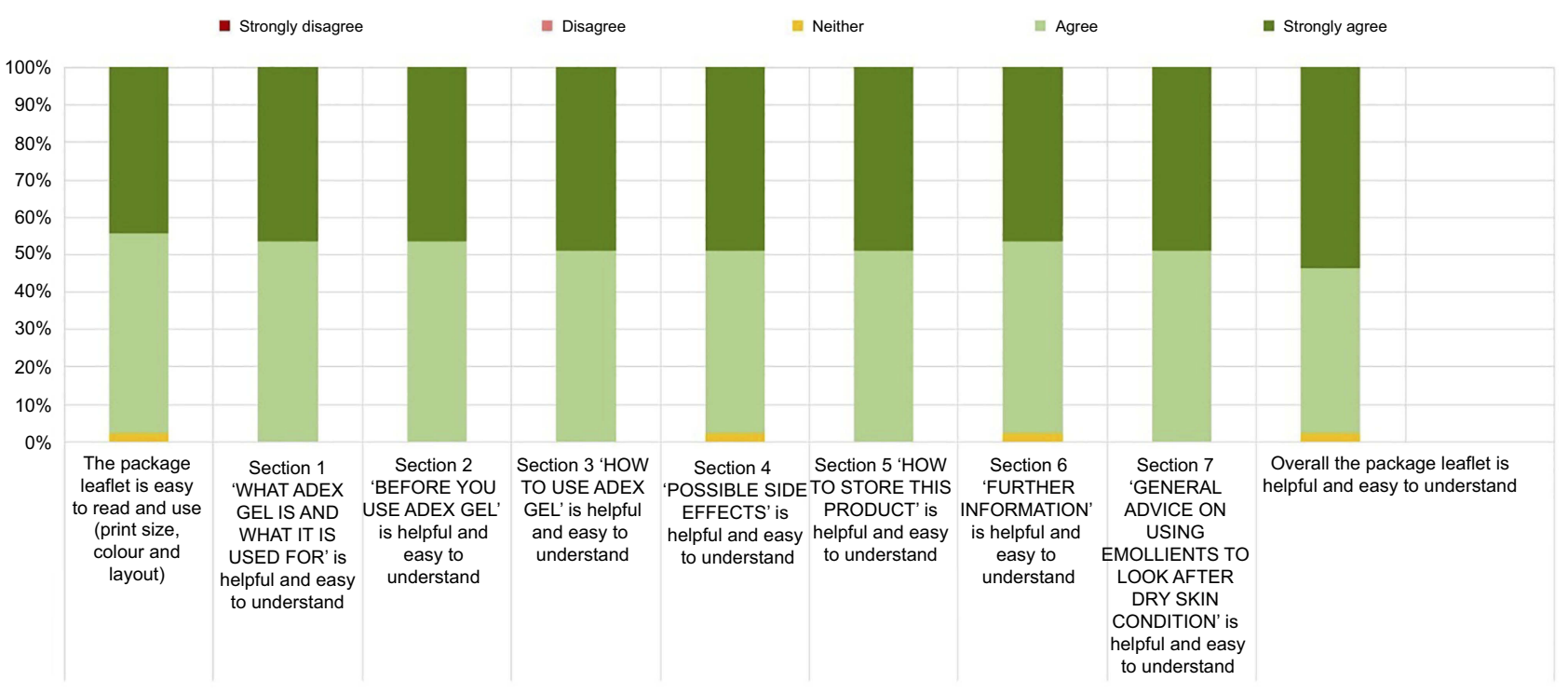

Figure 3 Packaging leaflet acceptability.

Table 3 Part 2 - Skin condition frequency table

\begin{tabular}{|l|l|l|}
\hline \multicolumn{2}{|l|}{ Skin Conditions Frequency Table } & $\%$ \\
\hline Skin Condition & No. Patients & 5 \\
\hline Dermatitis & 1 & 45 \\
Eczema & 9 & 50 \\
Psoriasis & 10 & 100 \\
Total & 20 & \\
\hline
\end{tabular}

Table 4 Part 2 - Emollients used

\begin{tabular}{|l|l|l|}
\hline \multicolumn{2}{|l|}{ Emollients Used Frequency Table } \\
\hline Emollient Name & No. Patients* & $\%$ \\
\hline Aveeno & 8 & 40 \\
Oilatum & 4 & 20 \\
Diprobase & 3 & 15 \\
Zerobase & 2 & 10 \\
E45 & 2 & 10 \\
Doublebase & 2 & 10 \\
m-folia & 1 & 5 \\
Epaderm & 1 & 5 \\
Hydromol & 1 & 5 \\
Sudocrem & 1 & 5 \\
No emollient & 2 & 10 \\
Total & 20 & 100 \\
\hline
\end{tabular}

Note: *Some patients used more than one emollient.

be useful where an emollient alone is not sufficient, and may help reduce reliance on supplementary use of corticosteroids or reduce the amount or potency of such additional agents used to manage the condition.
Table 5 Part 2 - Other products used

\begin{tabular}{|c|c|c|}
\hline Product Class & $\begin{array}{l}\text { No. } \\
\text { Patients* }\end{array}$ & $\%$ \\
\hline Topical Steroid & 9 & 45 \\
\hline Immunomodulators & 3 & 15 \\
\hline Vitamin D analogues & 2 & 10 \\
\hline $\begin{array}{l}\text { Vitamin D analogues / Corticosteroids } \\
\text { (combination) }\end{array}$ & 2 & 10 \\
\hline No other treatments & 7 & 35 \\
\hline Total & 20 & 100 \\
\hline
\end{tabular}

Note: *Some patients used more than one additional product to treat their skin condition.

Nicotinamide is a water-soluble vitamin, part of the vitamin B group and has, among its recognised actions, skin conditioning and anti-inflammatory properties. ${ }^{15}$ In essence, nicotinamide is an inhibitor of poly (ADP-ribose) polymerase-1 (PARP-1) enzyme. As this enzyme has ability to enhance nuclear factor kappa B-mediated transcription, it plays a key role in the expression of chemokines, inflammatory cytokines and inflammatory mediators. In addition, nicotinamide is an antioxidant agent with the ability to increase ceramide synthesis in the skin.

Nicotinamide's well-established safety, and its associated flexibility in dosage and area of application, therefore make it a particularly suitable contender for use in an emollient combination product. DENI is a novel nicotinamide-containing emollient gel and in this study, we 


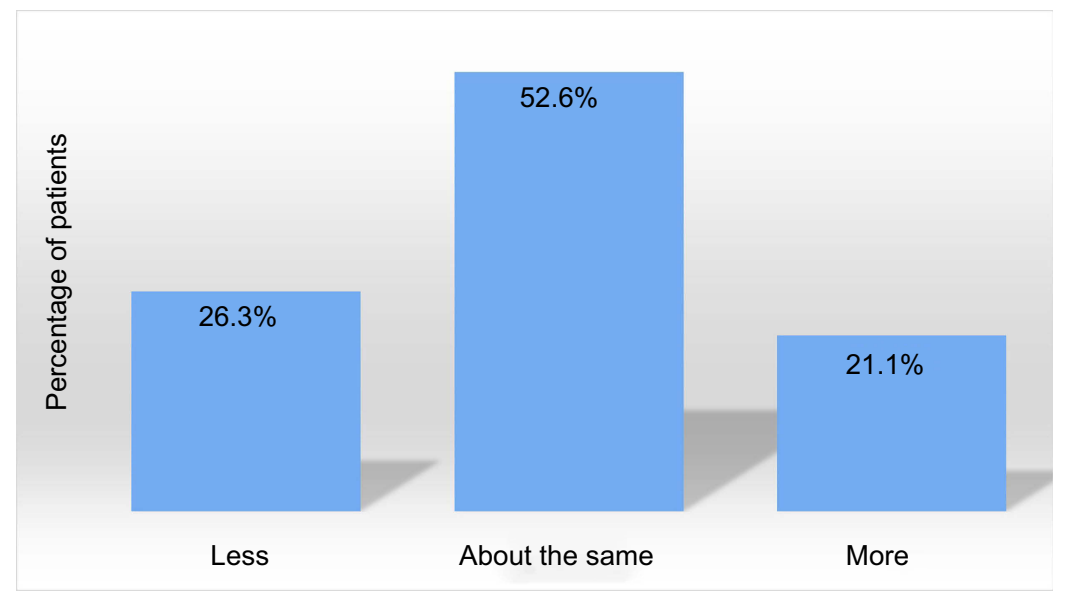

Figure 4 Q: Thinking about your skin condition and the effectiveness of treatment over the last four weeks, did you need to use less, about the same or more DENI gel than the amount of your usual emollient(s) which you would have expected to use? $(n=19)$.

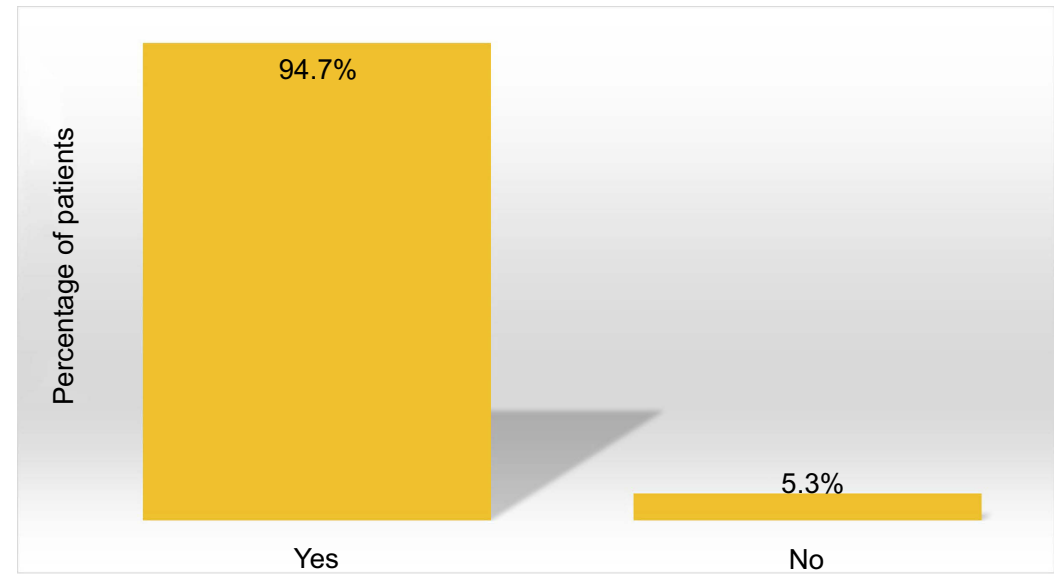

Figure 5 Q: Overall, would you say your skin condition has benefited from using DENI gel? $(n=19)$.

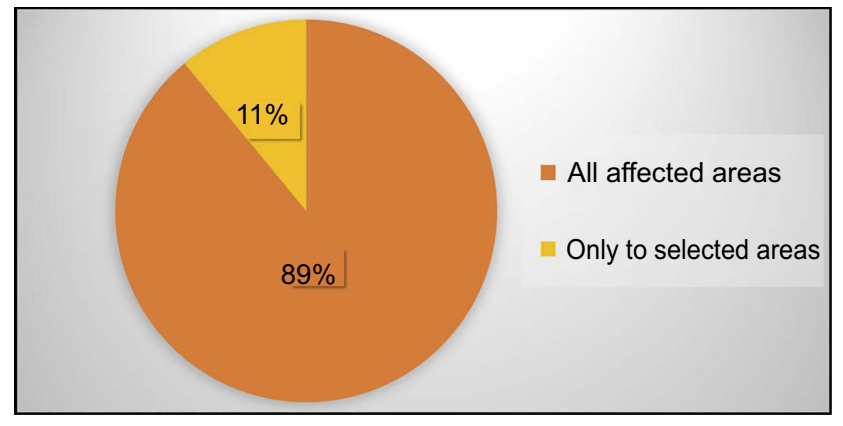

Figure 6 Q: Did you apply DENI gel to all affected skin areas, or only to selected areas?

assessed its clinical performance and acceptability, and its potential for reducing patients' reliance on topical corticosteroids and immunomodulators.

As expected, patients' responses with regard to DENI gel were very positive, ranging from $81 \%$ to $100 \%$ agreement regarding key clinical performance attributes including beneficial effects on skin moisturisation, soothing, smoothing, softening and making the skin feel more comfortable. Key acceptability attributes, including the gel's consistency, ease of application and absorption into the skin were also very high. These effects could be attributed to a high oil content and the presence of a humectant glycerol in the formulation.

More than half of patients reported that they needed to use less of their other anti-inflammatory treatments, such as corticosteroids, and nearly $95 \%$ reported that they felt their skin condition had benefited from using DENI gel. This has been also confirmed by the Medical Investigator who considered that for nearly all patients, DENI gel was a helpful and convenient addition to their treatment regime. These observations are in line with published studies attesting to the effectiveness of 


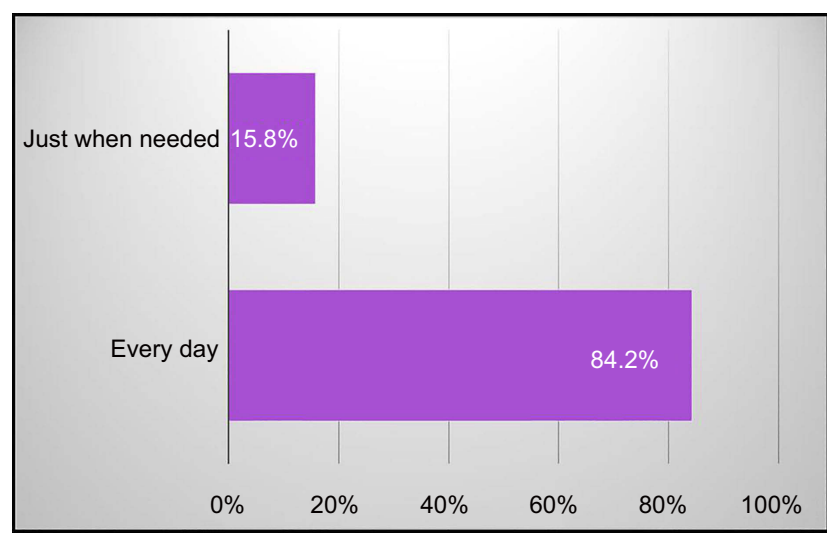

Figure 7 Q: Did you use DENI gel every day over the past four weeks, or just when you felt you needed it? $(n=19)$.

topically applied nicotinamide in inflammatory skin conditions including AE and psoriasis. ${ }^{15-18}$ The limitation of the study is that patients received samples labelled, but unblinded, as they would normally do in real-life settings when they get their emollient product (s) on prescription. The Medical Investigator was also aware which emollient was tested. Furthermore, the sample size is relatively small and future studies will need to cover a cohort of a larger population.

\section{Conclusion}

The results of this study provide evidence that DENI gel, an anti-inflammatory emollient gel containing nicotinamide, is a well-tolerated and effective product that may reduce reliance on topical corticosteroids and immunomodulators in patients with dry and/or inflamed skin conditions such as various forms of eczema and psoriasis.

\section{Acknowledgments}

This study was sponsored by Dermal Laboratories Ltd, Hitchin, UK and carried out by Alba Science, Edinburgh, UK. The abstract of this paper was presented at the $15^{\text {th }}$ EADV Spring Symposium, May 2018, Budva, Montenegro as a poster presentation.

\section{Disclosure}

All authors are currently employed by Dermal Laboratories Ltd. The authors report no other conflicts of interest in this work.

\section{References}

1. Williams H, Stewart A, von Mutius E, Cookson W, Anderson HR. Is eczema really on the increase worldwide? J Allergy Clin Immunol. 2008;121(4):947-954. doi:10.1016/j.jaci.2007.11.004

2. Kownacki S. The importance of emollients in treating the increasing incidence of atopic eczema. Nurs Times. 2009;105:28.

3. Clark C. How to chose a suitable emollient? Pharm J. 2004;273:351-353.

4. Cork MJ, Danby S. Skin barrier breakdown: a renaissance in emollient therapy. $B r \quad J$ Nurs. 2009;18(14):872-877. doi:10.12968/ bjon.2009.18.14.43356

5. NICE. Management of Atopic Eczema in Children from Birth up to the Age of 12 Years. National Institute for Health and Clinical Excellence; 2007. Available from: https://www.nice.org.uk/gui dance/cg57/resources/atopic-eczema-in-under-12s-diagnosis-and-man agement-pdf-975512529349. Accessed July 9, 2019.

6. Rawlings AV, Canestrari DA, Dobkowski B. Moisturizer technology versus clinical performance. Dermatol Ther. 2004;17:49-56. doi:10.1111/dth.2004.17.issue-s1

7. NICE. Guidance on use of topical corticosteroids in atopic eczema. Nurs Times. 2004;38:26-27.

8. Chase EP, Armstrong AW. Advances in management of atopic dermatitis: new therapies and novel uses of existing treatments. Semin Cutan Med Surg. 2012;31:17-24. doi:10.1016/j.sder.2011.11.005

9. Lucky AW, Leach AD, Laskarzewski P, Wenck H. Use of an emollient as a steroid-sparing agent in the treatment of mild to moderate atopic dermatitis in children. Pediatr Dermatol. 1997;14:321-324.

10. Darsow U, Wollenberg A, Simon D, et al. ETFAD/EADV eczema task force 2009 position paper on diagnosis and treatment of atopic dermatitis. JADV. 2010;24:317-328.

11. Drugs, Therapeutics, Bulletin. Topical steroids for atopic dermatitis in primary care. Drug Ther Bull. 2003;41:5-8.

12. NICE. Frequency of Application of Topical Corticosteroids for Atopic Eczema. National Institute for Health and Clinical Excellence; 2004. Available from: https://www.nice.org.uk/guidance/ta81/resources/fre quency-of-application-of-topical-corticosteroids-for-atopic-eczemapdf-2294813945797. Accessed July 9, 2019.

13. De Belilovsky C, Roo-Rodriguez E, Baudouin C, et al. Natural peroxisome proliferator-activated receptor-alpha agonist cream demonstrates similar therapeutic response to topical steroids in atopic dermatitis. J Dermatolog Treat. 2011;22:359-365. doi:10.3109/ 09546634.2010.499932

14. Msika P, De Belilovsky C, Piccardi N, et al. New emollient with topical corticosteroid-sparing effect in treatment of childhood atopic dermatitis: SCORAD and quality of life improvement. Pediatr Dermatol. 2008;25:606-612. doi:10.1111/j.1525-1470.2008.00783

15. Namazi MR. Nicotinamide: a potential addition to the anti-psoriatic weaponry. Faseb J. 2003;17:1377-1379. doi:10.1096/fj.03-0002hyp

16. Chen AC, Damian DL. Nicotinamide and the skin. Australas $J$ Dermatol. 2014;55:169-175. doi:10.1111/ajd.12163

17. Levine D, Even-Chen Z, Lipets I, et al. Pilot, multicenter, doubleblind, randomized placebo-controlled bilateral comparative study of a combination of calcipotriene and nicotinamide for the treatment of psoriasis. J Am Acad Dermatol. 2010;63:775-781. doi:10.1016/j. jaad.2009.10.016

18. Siadat AH, Siadat A, Iraji F, Jary M. Topical nicotinamide in combination with calcipotriol for the treatment of mild to moderate psoriasis: a double-blind, randomized, comparative study. Adv Biomed Res. 2013;2:90. doi:10.4103/2277-9175.122520 


\section{Publish your work in this journal}

Clinical, Cosmetic and Investigational Dermatology is an international, peer-reviewed, open access, online journal that focuses on the latest clinical and experimental research in all aspects of skin disease and cosmetic interventions. This journal is indexed on CAS.
The manuscript management system is completely online and includes a very quick and fair peer-review system, which is all easy to use. Visit http://www.dovepress.com/testimonials.php to read real quotes from published authors.

Submit your manuscript here: https://www.dovepress.com/clinical-cosmetic-and-investigational-dermatology-journal 